\title{
Behavioral Outcomes among Children of Alcoholics During the Early and Middle Childhood Years: Familial Subtype Variations
}

\author{
Leon I. Puttler, Robert A. Zucker, Hiram E. Fitzgerald, and C. Raymond Bingham
}

\begin{abstract}
This study examined early behavioral outcomes among young children of alcoholics (COAs) as a function of differences in subtype of paternal alcoholism. Participants were 212 children (106 girls and 106 boys, ages 3 through 8 ) and both of their biological parents. Families were characterized as antisocial alcoholics, nonantisocial alcoholics, and nonalcoholic controls. There were significant familial subtype group differences on parent report measures of children's total behavior problems, externalizing behavior, and internalizing behavior, and on measures of children's intellectual functioning and academic achievement. In all instances, COAs had poorer functioning than controls. In the behavior problem domain, but not for the domain of intellectual functioning, children from antisocial alcoholic families had greater problems than children from nonantisocial alcoholic families. In addition to the subtype effects, boys had higher levels of behavior problems than girls in all three areas, and oider children had more internalizing problems than younger children. Matemal functioning pertaining to lifetime alcohol problem involvement and antisocial behavior also contributed to child subtype differences in internalizing behavior. Results indicate that, even at very early ages, male and female COAs are heterogeneous populations that are distinguishable by way of familial subtype membership, as well as distinguishable from their non-COA peers. Thus, findings underscore the need to consider the heterogeneity of alcoholism when looking at its effects on child development.
\end{abstract}

Key Words: Familial Alcoholic Subtypes, Early Vulnerabilities, Child Behavior Problems, Intellectual Functioning, Gender Differences.

$\mathbf{I}^{\mathrm{N}}$ N TRYING to understand the etiology of alcoholism, a central methodological strategy is to study individuals who are at high risk for the disorder. Children of alcoholics (COAs) are a high-risk population. Reviews of the literature $^{1-3}$ indicate that male and female COAs are more likely to become alcoholic than children with nonalcoholic parents. This risk is higher for male COAs. In addition to alcohol problems, male and female COAs have been shown

From the Departments of Psychiatry (L.I.P., R.A.Z) and Psychology (R.A.Z.) and the Alcohol Research Center (L.I.P., R.A.Z.), University of Michigan, Ann Arbor, Michigan; Department of Psychology (H.E.F.), Michigan State University, East Lansing, Michigan; and the Serious Mental Illness Treatment, Research, and Evaluation Center (C.R.B.), Veterans Administration Medical Center, Ann Arbor, Michigan.

Received for publication October 11, 1996; accepted September 1, 1998

This work was supported by Grant R01 AA-07065 from the National Institute on Alcohol Abuse and Alcoholism (to R.A.Z. and H.E.F.).

Reprint requests: Leon I. Puttler, Michigan State University-University of Michigan Longitudinal Study, 4660 South Hagadom Road, Suite 620, East Lansing. MI 48823.

Copyright (C) 1998 by The Research Society on Alcoholism. to be at elevated risk for other biological, psychological, and social difficulties. ${ }^{1-3}$ However, many individual COAs do not develop significant problems either as children or adults. ${ }^{3}$ Thus, there has been an increased emphasis on trying to elucidate factors that increase or decrease risk in COAs. The study of these individual differences has already provided evidence for early developmental problems that may ultimately prove to be pathways into later alcoholism. ${ }^{4-6}$

The extant literature on subtypes has also clearly demonstrated that alcoholism is a heterogeneous disorder. ${ }^{7-10}$ Observed differences among alcoholic subtypes clearly suggest different developmental pathways and different biopsychosocial processes involved in their creation. ${ }^{11-13}$ There is also evidence that these pathways and processes are different for women than for men. ${ }^{14-18}$

Although studying COAs is a means of identifying early developmental issues that are linked to future alcoholrelated problems, as well as other difficulties, a shortcoming of previous investigations has been their reliance on samples of males. ${ }^{3,19}$ Moreover, studies that included female COAs have often failed to analyze the data for potential gender differences (e.g., Refs. 20 and 21). Some studies, however, have investigated gender differences with results, suggesting at least some gender differences among COAs. ${ }^{5,19}$ Specifically, risk factors within the family environment were found to have a larger role in the functioning of sons than daughters among children, ${ }^{5}$ whereas family history of alcoholism showed greater effects for women than men in a college-aged sample. ${ }^{19}$ Still lacking, though, is the possible contribution of alcoholism subtype variation within families as a potential source of risk variation within children.

The present study is one of a series that explores this issue within the context of a cumulation/nesting theory for the aggregation of parental and familial risk. ${ }^{12,13,22}$ The theory posits that, as risk at the parental and familial level aggregates, a variety of pathways produce aggregation of child risk. This, in turn, leads to the eventual emergence of the adult outcome of alcohol-related difficulties.

The work began with the observation that one of the major differentiating characteristics of the adult alcoholic phenotype is the presence or absence of high lifetime levels of antisocial involvement. A variety of co-occurring at- 
tributes have been observed using this subtyping strategy, including differences in level of severity of alcoholic symptomatology, differences in other psychopathology and measures of nonalcoholic life course adaptation, and family pedigree variations that reflected potential differences in heritability of the disorder. ${ }^{13}$ This subtyping strategy, with some minor variation, is close to the one pertaining to differences between alcoholism with sociopathy (or antisocial personality disorder), ${ }^{23,24}$ type $\mathrm{B}$ alcoholism, ${ }^{25}$ and their nonantisocial variants. However, the subtyping scheme we used more explicitly contained a developmental stipulation; namely, that subtyping had to be made on the basis of the presence of a high-level history of antisocial involvement in both childhood and adulthood. Men with this pattern of alcoholism and co-occurring high life-course antisociality were categorized as antisocial alcoholics (AALs), and those without such a history were classified as nonantisocial alcoholics (NAALs).

Although this subtyping approach is similar to one based on an adult diagnosis of antisocial personality disorder, it approaches the problem developmentally. It also takes into account a theory concerning the processes of acquisition of alcohol abuse-dependence with this particular type of comorbidity. These processes include the development of patterns of rule-breaking, troublemaking, and early peer involvement, which introduce the person to a deviant peer network and sustain the deviant behavior once it is in place. ${ }^{22,26}$ On those grounds, the theory also posits that deviant peer associations should lead to an assortative pattern of mating among such men, and the concomitant development of different patterns of parenting between the men and their partners. In turn, this pattern creates earlier and greater psychosocial impairment among their offspring, which evolves into an earlier and more problematic course of alcohol and other drug involvement later in childhood. If this conceptual base is correct, the antisocial-nonantisocial distinction among these men would be an effective marker for familial aggregation of risk and, ultimately, for child differences in risky behavior.

Two parallel studies by our group ${ }^{27,28}$ have provided evidence that the familial structure in AAL families, in fact, differs from that of both NAALs and nonalcoholic control families. In AAL families, the perceptions of spouses were more blaming and distrustful, there was greater marital conflict, and the communication patterns for problemsolving were less effective. The next step was to test the theory relating to aggregation of risk in spouses of AAL versus NAAL men, as well as to examine whether differences in child functioning in AAL, NAAL, and control families could be established. This work was conducted on families from the first wave of the ongoing Michigan State University-University of Michigan (MSU-UM) Longitudinal Study, ${ }^{26}$ a prospective, high-risk study of the development of alcohol abuse/dependence, other drug problems, and related life difficulties that began with preschool-aged boys and both of their biological parents (Zucker et al. unpublished data). Because the study originally recruited boys, with a girls' component added later, earlier reports from the study have only been able to focus on the boys and their parents. In that work, (Ellis et al. unpublished data) risk factors for child behavior problems were more strongly aggregated in AAL than in NAAL or control families. Even though these families had only been selected for risk by way of the father's alcoholism, AAL families had higher levels of parent psychopathology among mothers as well as fathers, more family aggression, a denser family history of alcoholism, and more difficult child temperament among their offspring. In addition, the boys from these AAL families also experienced the highest levels of behavior problems (both externalizing and internalizing), with one-fifth of the boys identified as having clinically significant behavioral impairment. Boys from NAAL families generally occupied an intermediary risk status in behavioral impairment and did not differ from boys from control families on a number of contrasts (e.g., internalizing behavior and hyperactivity).

The current study extends this work by: (1) adding the study of girls in these families, (2) extending the evaluation of child functioning into the early school years, and (3) exploring potential gender differences. The goal of this research is to detail early developmental pattern variations that might lead to future behavioral difficulty. It is the first known study to investigate potential differential effects relating to paternal alcoholic subtype on both male and female children. Given the already noted differences between AAL, NAAL, and control families, it was hypothesized that child risk should model differences already observed between the parents and involve higher levels of behavior problems, lower performance on measures of executive functioning (e.g., IQ), and poorer performance on measures of school achievement for children from AAL, compared with NAAL and control, families.

\section{METHODS}

\section{Participants}

The present sample is a subset of 212 families drawn from the larger MSU-UM Longitudinal Study ${ }^{9,26,29}$ that allows the contrast of gender differences. Table 1 shows the sample, which consists of all families in the larger project having a female child between the ages of 3 through 8 ( $n=$ 106), and a matched sample of boys (matched in terms of Risk Group Status within each Age Cohort based on fathers' alcoholism and antisociality criteria) randomly selected from the remainder of recruited families having a boy between the ages of 3 through $8(n=106)$. Although all the female target children (FTCs) in the present study have brothers also involved in the data collection process of the larger project, none of the 212 children participating in the current study include brothers and sisters. This selection procedure eliminates bias that might result from having children in the study sharing common environmental and genetic influences. Girls were categorized as coming from AAL, NAAL, or control families based on criteria described under "Alcoholic Subtype." In selecting the boys for inclusion in the present sample, all 3-through 5-year-old boys from AAL families in the larger study were identified, and 14 boys 
Table 1. No. of AAL, NAAL, and Control Families Across Ages $3-8(n=212)$

\begin{tabular}{|c|c|c|c|c|c|c|c|}
\hline \multirow[b]{3}{*}{ Age cohort } & \multicolumn{7}{|c|}{ Familial risk group } \\
\hline & \multicolumn{2}{|c|}{ AAL } & \multicolumn{2}{|c|}{ NAAL } & \multicolumn{2}{|c|}{ Control } & \multirow[b]{2}{*}{ Age cohort Totals } \\
\hline & Boys & Girls & Boys & Girls & Boys & Giris & \\
\hline $3-5$ & $14(16 \%)$ & $14(16 \%)$ & $31(23.5 \%)$ & $31(23.5 \%)$ & $21(10.5 \%)$ & $21(10.5 \%)$ & 132 \\
\hline $6-8$ & $8(10 \%)$ & $8(10 \%)$ & $16(20 \%)$ & $16(20 \%)$ & $16(20 \%)$ & $16(20 \%)$ & 80 \\
\hline Risk Group Totals & \multicolumn{2}{|c|}{44} & \multicolumn{2}{|c|}{94} & \multicolumn{2}{|c|}{74} & \\
\hline
\end{tabular}

Note: Percentages in the table are the percentage of Risk Group families for that target child age period (i.e., individual cell $n /$ Age Cohort $n$ ).

who did not have a sister in the sample were randomly selected (to parallel the previously identified fourteen 3-through 5-year-old girls coming from AAL families). A similar process of identifying boys for inclusion was conducted for each of the other Risk Group $\times$ Age Cohort combinations (cf. Table 1).

The MSU-UM Longitudinal Study is an ongoing project that involves a population-based sample of alcoholic men, their partners (among whom alcohol abuse/dependence status was free to vary), their initially 3through 5-year-old son, and a 3-through 11-year-old daughter (if present in the family). The sample also includes a contrast group of nonsubstanceabusing families with like aged male and female children, who were drawn from the same neighborhoods where the alcoholic families resided (see Zucker et al. ${ }^{13}$ for a more complete description of the recruitment procedure).

Families are assessed at 3-year intervals beginning at wave 1, when the target children were ages 3 through 5 . When there were multiple female siblings in the family, the FTC chosen for inclusion was alternated among families between the older and younger sibling of the male target child (MTC). Inclusion criteria for the FTC also required that she be the biological full sibling of the MTC being studied.

Data in the present report were from the FTC's first data collection wave, although all of the older boys ( 6 through 8 years of age) in the current study had one previous data collection point when they were between the ages of 3 through 5 . The children ranged in age from 3 through 8 (mean $=5.63 ; \mathrm{SD}=1.80$ ). Thus, the current study involves only cross-sectional, rather than longitudinal, data. As was the case when originally recruited into the study, neither parent in control families met DSM-IV ${ }^{31}$ criteria for alcohol abuse, alcohol dependence, nor other drug abuse/dependence. One hundred thirty-eight families were alcoholic, whereas 74 were nonalcoholic controls. All families were Caucasian, because non-Caucasian ethnic and racial groups made up $<4 \%$ of the population meeting the necessary family inclusion criteria in the area where we sampled. Given the extensive literature demonstrating a substantial relationship between patterns of alcohol/substance involvement and ethnic/racial status, ${ }^{32,33}$ and the fact that effective analyses for such differences could not be undertaken with the proposed study sample size, it was decided to exclude such variation rather than have it contribute to error.

\section{Procedure}

Data were collected by trained project staff who were blind to family diagnostic status. Due to the large amount of data collected, a number of contacts with the family were necessary. This number differed, dependent on the age of the target child. The visits involved $\sim 9$ to $10 \mathrm{hr}$ of contact time with each parent and $7 \mathrm{hr}$ of contact time with each target child. Contacts included questionnaire sessions, semistructured interviews, and interactive tasks. The measures used in the present study are the subset of these instruments pertaining to issues of child problem behavior, cognitive functioning, and academic achievement. Most of the contacts occurred in the families' homes, although one contact for the interactional assessment occurred on the university campus. Special arrangements were also made to collect data from families that had relocated from the study's original recruitment site. No families have been lost to the study through relocation, although $1 \%$ of the parents (all fathers) have died since the study's inception.

\section{Measures}

Parent Measures. Family Demographics. Demographic information came from a questionnaire assessing education, occupation, family income, parents' occupation, and marital history. Because data from different families were collected during the interval between 1985 and 1996, family income has been adjusted for inflation to 1996 dollars using the Gross Domestic Product Implicit Price Deflator Index. ${ }^{34}$ Socioeconomic status (SES) of participants was calculated using the Duncan TSEI2 Socioeconomic Index ${ }^{35}$ an occupationally based measure of social prestige. Significant evidence exists in the sociological literature to suggest that occupation, not income or education, is the optimal indicator of SES and that the perceived prestige of an occupation best captures its underlying socioeconomic dimension. ${ }^{36}$ To obtain a measure of SES that would best capture the environment of the target child, family SES was calculated using an average of the mother's and father's SES when both parents worked, and the employed parent's score when only one parent worked. Special scores reflecting the lowest possible Duncan ratings were used for families in which neither parent was employed.

Parental Alcoholism. All parents completed the Short Michigan Alcohol Screening Test (SMAST), ${ }^{37}$ the Diagnostic Interview ScheduleVersion III (DIS), ${ }^{38}$ and the Drinking and Drug History Questionnaire. ${ }^{39}$ The SMAST is a well-validated screening inventory used to assess alcohol problems, consisting of 13 items with "Yes"/"No" responses.

The DIS ${ }^{38}$ is a structured diagnostic interview that allows trained lay interviewers to gather extensive information about physical, alcoholrelated, and drug-related symptoms, as well as other areas of psychiatric symptomatology. Although the entire DIS was administered to each parent, only the information from the alcohol section was used in this study.

The Drinking and Drug History Questionnaire ${ }^{39}$ gathers information about the informant's alcohol/other drug use and problems. Here also, only information from the alcohol section was used for the present work. This section focuses on the amount of alcohol consumption in the past 6 months. In the Lifetime Version of this instrument (given at the time the family entered the study), the questionnaire also inquires about the largest amount of alcohol consumed during a 24-hr period at any point in the participant's life. Finally, the instrument asks the participant whether $\mathrm{s} / \mathrm{he}$ has experienced various problems as a result of alcohol use and, if so, the frequency of these problems.

A diagnosis of alcohol abuse/dependence was made by a trained clinician using DSM-IV ${ }^{31}$ criteria based on information provided on the Drinking and Drug History Questionnaire (Zucker et al. unpublished questionnaire), the SMAST, ${ }^{37}$ and the DIS. ${ }^{38}$ A positive lifetime diagnosis for alcoholism was made if the individual met at least DSM-IV alcohol abuse criteria during their children's lives. In the current study, 138 of the 212 families had a father meeting such criteria, and these families comprised the two alcoholic groups. Nine other fathers met alcohol abuse/ dependence criteria, but all drinking problems had ceased by the age of 22 , and no children had been born by this point. These nine families fit the Developmentally Limited Alcoholism subtype described by Zucker ${ }^{10}$ and were therefore classified as controls, rather than alcoholics, because of the absence of significant alcohol problems during adulthood. In the remaining 65 families, neither parent had ever met abuse nor dependence criteria. These families comprised the remainder of the control group.

Antisocial Behavior. The Antisocial Behavior Checklist (ASB) ${ }^{41}$ was used to assess antisocial behavior (Zucker and Noll unpublished data). 
The ASB is a 46-item revision of an earlier antisocial behavior inventory used in the Rutgers Community Study ${ }^{42,43}$ that has been modified so that items are also salient for adult antisocial activity. The questionnaire measures the frequency of the parent's participation in a variety of aggressive and antisocial activities. Antisocial behavior is measured in both childhood (e.g., being suspended or expelled from school for fighting, lying to parents, running away from home for more than a day) and adulthood (e.g., defaulting on a debt, being fired for absenteeism, resisting arrest) domains.

A series of reliability and validity studies (Zucker et al. unpublished data) with populations ranging from male and female college students to male and female jail inmates, has shown that the instrument has adequate test-retest reliabilities ( 0.91 over 4 weeks) and internal consistency reliability ( $\alpha=0.93$ ). The instrument also differentiates between individuals with long histories of antisocial behavior (e.g., prisoners) versus individuals with minor offenses in district courts versus university students, and strongly discriminates those with antisocial personality disorder from those without this disorder. ${ }^{30}$

Alcoholic Subtype. In order for children from alcoholic families to be identified as offspring of AALs or NAALs, their fathers were classified as one or the other alcoholic subtype. Fathers' scores on the ASB were summed over both childhood and adulthood domains. To be classified as an AAL, the father had to attain a score of 10 or higher on both domains. ${ }^{13}$ By using both childhood and adulthood antisocial behavior, rather than a classification based solely on adult functioning to determine alcoholic subtype, the procedure ensured that high-scoring participants had established a developmental trajectory that began early in life with aggressive/antisocial behavior, then moved thereafter into sociopathy during adulthood (i.e., that they exhibited high levels of antisocial behavior both as a child and adult). Thus, the life history for high-scoring participants (AALs) involved a pattern of sustained antisociality, rather than one that was potentially a more epiphenomenal adaptation of aduit life.

As noted in the introduction, the Zucker et al. ${ }^{13}$ study has been successful in distinguishing AALs from NAALs regarding age of onset, severity, number, life course of alcohol problems, measures of social adaptation, amount and severity of other psychopathology, and salience of family history load for alcoholism. Moreover, although this classification scheme only uses paternal alcoholism and antisociality as the basis for categorization, a substantial amount of other data indicates that the scheme is related to other differences in family functioning (e.g., spousal psychopathology, SES, and marital aggression). ${ }^{30}$

Lifetime Alcohol Problems Score. To determine a parent's degree of alcohol-related difficulty over the life course, the Lifetime Alcohol Problems Score (LAPS) ${ }^{45}$ was used. LAPS incorporates information on the primacy (onset), variety, and degree of life invasiveness of drinking problems. Information from which LAPS was coded was obtained from the Drinking and Drug History Questionnaire, ${ }^{39}$ the SMAST, ${ }^{37}$ and the DIS ${ }^{38}$ during the family's initial assessment with the project at wave 1 .

LAPS consists of three component subscores: (1) the primacy component, or squared inverse of age of first drunkenness; (2) the variety component, or number of areas in which drinking problems are reported; and (3) the life percent component, or measure of the interval between most recent and earliest drinking problem corrected for current age. The measure effectively distinguishes between alcoholics and nonalcoholics, and among levels of severity of DSM-III- $\mathrm{R}^{46}$ alcohol dependence. ${ }^{45,47}$ The index is also correlated with a wide range of external measures of alcoholrelated difficulty, such as blood alcohol concentration level at arrest and treatment involvement.

Child Measures. Child's Current Behavior. Each parent completed the Achenbach Child Behavior Checklist-Parent Version (CBCL), ${ }^{48}$ which was used to assess child behavior problems. Test-retest reliability of the $\mathrm{CBCL}$ has been shown to range from 0.95 over a 2-week interval, to 0.84 over a 3-month interval, whereas parent agreement on CBCL scores falls between 0.62 and $0.69 .^{48}$ External validity of the $\mathrm{CBCL}$ is adequate, with parent $C B C L$ ratings related to independent raters' perceptions of the child. $^{49}$

The CBCL yields scores on two Broadband factors reflecting external- izing and internalizing behavior, and provides an overall index of child behavior problems known as the Total Behavior Problem score. The $\mathrm{CBCL}$ also yields scores on a number of Narrowband factors, but these factors were not used in analyses of the current study to avoid the inherent overlap between scores on Broadband and Narrowband factors. $T$-scores (that are normed within gender) were calculated for all the CBCL scales to make analyses across child gender more meaningful.

Intellectual Functioning. Current general intellectual functioning for children ages six or older was measured with the Wechsler Intelligence Test for Children-Revised (WISC-R) ${ }^{50}$ The WISC-R, a commonly used intelligence measure, was developed for use with children ages 6 through 16. It consists of 12 subtests, with 6 assessing Verbal skills and 6 assessing Performance skills. Scaled scores were calculated for each subtest. In addition, a Verbal IQ, a Performance IQ, and a Full-Scale IQ score were calculated.

The WISC-R was normed on groups that are representative of the U.S. population of children. ${ }^{50}$ The average internal reliability coefficients across the entire age range for the Verbal IQ, Performance IQ, and Full-Scale IQ were $0.94,0.90$, and 0.96 , respectively. Test-retest reliabilities were similar to those obtained for internal consistency. Adequate validity of the instrument has been established through correlations with other individually administered intelligence tests.

Intellectual functioning in children below the age of six was assessed with the Third Revision (Form L-M) of the Stanford-Binet Intelligence Scale (Stanford-Binet). ${ }^{51}$ The Stanford-Binet, another commonly used measure of intelligence, consists of subtests designed to measure general mental adaptability. It is used with children as young as age two, as well as with adults. An overall IQ was obtained by calculating the child's obtained Mental Age and comparing it with his or her Chronological age.

Although different IQ measures (Stanford-Binet vs. WISC-R) were administered, depending on the age of the child, scores from these two measures are quite similar, with correlations between Full-Scale IQ on the WISC-R and the Stanford-Binet IQ reported to be $0.82 .{ }^{52}$ The only psychometric difference between the two measures is the standard deviation; the WISC-R has a standard deviation of 15, whereas the StanfordBinet has a standard deviation of 16 . To allow pooling of these two sets of data, Stanford-Binet IQs were restandardized to a standard deviation of 15 , thus allowing them to be pooled with WISC-R scores.

Academic Achievement. The Wide Range Achievement Test-Revised (WRAT-R) ${ }^{53}$ was used to assess children's current academic achievement. The WRAT-R was designed to assess a child's skill in basic academic coding tasks. The test consists of three subtests (Reading, Spelling, and Arithmetic) and yields standard scores, percentiles, and grade ratings (the scores reported herein are the standard scores). It was standardized on a national sample of 5600 individuals, ranging in age from 5 to 74 . It is a widely used instrument with adequate reliability and validity. The WRAT-R was only given to children 6 years of age and older.

\section{RESULTS}

\section{Demographic Variables}

A 3 (Risk Group) $\times 2$ (Age Cohort) $\times 2$ (Child Gender) multivariate analysis of variance [MANOVA] was conducted on the following variables: Child's Age, Maternal Age, Paternal Age, Maternal Years of Education, Paternal Years of Education, Annual Family Income, and Family SES. Wilk's lambda was used for all multivariate $F$-tests. None of the interactions were significant. A main effect $[F(7,193)=56.16, p<0.01]$ was observed for the Age Cohort factor. Univariate ANOVAs showed significant differences only for Child's Age $[F(1,200)=378.11, p<0.01]$, confirming the obvious difference that 6 - through 8 -yearolds are older than 3- through 5-year-olds, and Maternal 
Table 2. Demographic Characteristics of AAL, NAAL, and Control Families

\begin{tabular}{|c|c|c|c|c|}
\hline \multirow[b]{3}{*}{ Variable } & \multicolumn{3}{|c|}{ Familial risk group } & \multirow[b]{3}{*}{ Univariate $F$} \\
\hline & \multirow{2}{*}{$\frac{\operatorname{AAL}\{n=44\}}{\operatorname{Mean}(\mathrm{SD})}$} & \multirow{2}{*}{$\frac{\text { NAAL }(n=94)}{\text { Mean }(S D)}$} & \multirow{2}{*}{$\begin{array}{c}\text { Control }(n=74) \\
\text { Mean (SD) }\end{array}$} & \\
\hline & & & & \\
\hline Child's Age & $5.80(1.91)$ & $5.52(1.95)$ & $5.66(1.51)$ & 2.55 \\
\hline Maternal Age & $31.16(4.45)$ & $33.28(4.29)$ & $33.14(4.12)$ & $3.70^{\star a c}$ \\
\hline Paternal Age & $34.23(5.17)$ & $34.97(5.33)$ & $34.42(4.70)$ & 0.46 \\
\hline Maternal Education (in yr) & $12.59(1.81)$ & $13.57(1.90)$ & $13.66(1.80)$ & $4.35^{+a c}$ \\
\hline Paternal Education (in yr) & $12.66(1.88)$ & $13.73(2.24)$ & $14.77(2.20)$ & $11.56^{\star \star a b e}$ \\
\hline Annual Family income & $32.07(20.24)$ & $47.90(23.34)$ & $52.50(21.88)$ & $11.89^{* * a c}$ \\
\hline Family SES & $291.11(112.80)$ & $353.80(150.68)$ & $390.41(146.64)$ & $6.71^{* * a c}$ \\
\hline
\end{tabular}

Note: Annual Family Income is represented in thousand dollar units.

" $p<0.05 ;{ }^{* *} \rho<0.01$ [ $d f=(2199)$ for all univariate tests]; ${ }^{a}$ AALs $<$ Controls; ${ }^{\circ}$ NAALs $<$ Controls; ${ }^{\circ}$ AALs $<$ NAALs.

Table 3. Means and SDs of Child Total Behavior Problems, Externalizing Behavior, Internalizing Behavior, and IQ Among Children in AAL, NAAL, and Control Families Across Ages 3-8

\begin{tabular}{|c|c|c|c|c|c|c|c|c|c|}
\hline \multirow[b]{4}{*}{ Variable } & \multirow{4}{*}{$\begin{array}{l}\text { Age } \\
\text { cohort }\end{array}$} & \multirow[b]{4}{*}{$n$} & \multicolumn{6}{|c|}{ Familial risk group } & \multirow{4}{*}{$\begin{array}{l}\text { Univariate } \\
\text { significant effects } \\
(p<0.05)\end{array}$} \\
\hline & & & \multicolumn{2}{|c|}{$\operatorname{AAL}(n=44)$} & \multicolumn{2}{|c|}{ NAAL $(n=94)$} & \multicolumn{2}{|c|}{ Control $(n=74)$} & \\
\hline & & & Boys & Girls & Boys & Giris & Boys & Girls & \\
\hline & & & Mean (SD) & Mean (SD) & Mean (SD) & Mean (SD) & Mean (SD) & Mean (SD) & \\
\hline CBCL Total & $3-5$ & 264 & $58.64(10.02)$ & $52.07(6.45)$ & $54.40(9.11)$ & $48.63(7.82)$ & $50.14(6.91)$ & $48.33(7.12)$ & $\mathrm{RG}, \mathrm{CG}$ \\
\hline $\begin{array}{l}\text { Behavior Problems } \\
\text { Familial Risk Group }\end{array}$ & $6-8$ & 160 & $56.38(8.75)$ & $50.63(5.91)$ & $53.25(8.45)$ & $52.09(9.05)$ & $48.94(8.60)$ & $52.09(9.05)$ & \\
\hline \multicolumn{3}{|l|}{$\begin{array}{l}\text { Familial Risk Group } \\
\text { Totals }\end{array}$} & \multicolumn{2}{|c|}{$54.68(8.61)$} & \multicolumn{2}{|c|}{$51.91(8.85)$} & \multicolumn{2}{|c|}{$48.56(8.19)$} & \\
\hline $\mathrm{CBCL}$ & $3-5$ & 264 & $59.43(10.05)$ & $54.04(6.45)$ & $54.60(9.01)$ & $49.77(7.78)$ & $50.31(6.80)$ & $50.74(7.44)$ & $\mathrm{RG}, \mathrm{CG}, \mathrm{RG} \times \mathrm{AC}$ \\
\hline $\begin{array}{c}\text { Externalizing Behavior } \\
\text { Familial Risk Group }\end{array}$ & $6-8$ & 160 & $57.19(9.32)$ & $52.63(6.69)$ & $53.34(6.81)$ & $55.22(8.27)$ & $48.28(9.08)$ & $48.16(8.96)$ & \\
\hline Total & & & \multicolumn{2}{|c|}{$56.07(8.62)$} & \multicolumn{2}{|c|}{$52.90(8.39)$} & \multicolumn{2}{|c|}{$49.53(8.00)$} & \\
\hline CBCL & $3-5$ & 264 & $51.96(7.66)$ & $49.57(6.64)$ & $50.45(9.40)$ & $46.71(7.43)$ & $47.93(8.26)$ & $45.60(8.03)$ & $\mathrm{RG}, \mathrm{AC}, \mathrm{CG}$ \\
\hline $\begin{array}{l}\text { Internalizing Behavior } \\
\text { Familial Risk Group }\end{array}$ & $6-8$ & 160 & $54.13(9.48)$ & $48.25(5.36)$ & $53.06(11.47)$ & $49.91(9.55)$ & $50.88(10.52)$ & $48.06(8.70)$ & \\
\hline \multicolumn{3}{|l|}{ Totals } & \multicolumn{2}{|c|}{$50.92(7.51)$} & \multicolumn{2}{|c|}{$49.57(9.43)$} & \multicolumn{2}{|c|}{$47.93(8.93)$} & \\
\hline \multirow[t]{2}{*}{ Full-Scale IQ } & $3-5$ & 132 & $99.00(13.23)$ & 102.95 (17.35) & $101.24(12.68)$ & $105.08(13.87)$ & $108.57(12.61)$ & $113.84(11.98)$ & $R G$ \\
\hline & $6-8$ & 80 & $104.00(14.26)$ & $102.88(13.68)$ & $103.94(14.15)$ & $106.25(14.72)$ & $104.25(14.98)$ & $109.88(9.76)$ & \\
\hline \multicolumn{10}{|l|}{ Familial Risk Group } \\
\hline Total & & & \multicolumn{2}{|c|}{$101.97(14.55)$} & \multicolumn{2}{|c|}{$103.82(13.60)$} & \multicolumn{2}{|c|}{$109.41(12.66)$} & \\
\hline
\end{tabular}

Note: RG, Risk Group; AC, Age Cohort; CG, Child Gender. CBCL scores are T-scores, and those shown are aggregated across Parent (Mother and Father) reports because there was no significant main effect for this factor.

Age $[F(1,200)=8.42, p<0.01]$, showing that mothers of 6 through 8-year-olds were older than mothers of 3- through 5 -year-olds. A main effect $[F(7,193)=2.21, p<0.05]$ was also observed for the Child Gender factor. Univariate ANOVAs showed significant differences only for Maternal Age $[F(1,200)=10.08, p<0.01]$ and Paternal Age $[F(1,200)=5.53, p<0.05]$. Mothers and fathers of girls $\left(\right.$ Mean $_{\text {mothers }}=33.83, \mathrm{SD}_{\text {mothers }}=4.14 ;$ Mean $_{\text {fathers }}=$ 35.57, $\mathrm{SD}_{\text {fathers }}=5.39$ ) were older than mothers and fathers of boys $\left(\mathrm{Mean}_{\text {mothers }}=31.75, \mathrm{SD}_{\text {mothers }}=4.28\right.$, Mean $_{\text {fathers }}=33.68, \mathrm{SD}_{\text {fathers }}=4.56$ ).

Table 2 shows means and standard deviations of the demographic characteristics of the sample by Risk Group, aggregated across both Age Cohort and Child Gender to better illustrate the main effect observed for the Risk Group factor in the above analysis $[F(14,386)=3.65, p<$ 0.01]. Univariate ANOVAs showed group differences for Maternal Age, Maternal Education, Paternal Education, Annual Family Income, and Family SES (see Table 2).

Post-hoc comparisons using the Tukey-Kramer Honestly
Significant Difference test (Tukey) with $\alpha=0.05$ were used to identify which groups differed (see Table 2). Mothers in AAL families were younger and had significantly less education than mothers in NAAL and control families. Fathers in AAL families had less education than fathers in NAAL and control families, and fathers in NAAL families had less education than fathers in control families. The Annual Family Income in AAL families was significantly lower than either NAAL or control families. Finally, AAL families had significantly lower SES than NAALs and controls.

\section{Child Outcome Variables}

Table 3 shows means and standard deviations for child behavior problems and intellectual functioning, as well as where significant univariate effects were observed. Factorial ANOVAs and MANOVAs were run on child outcome variables as described herein.

Child Behavior Problems. A 3 (Risk Group) $\times 2$ (Age Cohort) $\times 2$ (Child Gender) $\times 2$ (Parent) ANOVA was 
performed on Total Behavior Problems $T$-scores of the CBCL. A main effect for Risk Group was present $[F(2,400)$ $=14.90, p<0.01]$. Post-hoc comparisons indicated that children from AAL families had greater problems than children from NAAL and control families $(p<0.05)$. Children from NAAL families also had greater problems than children from control families $(p<0.05)$. A main effect for Child Gender $[F(1,400)=19.89, p<0.01]$ was also observed, with boys having greater problems than girls. No other main effects or interactions were significant.

Given the significant differences in the overall measure of Total Behavior Problems, a 3 (Risk Group) $\times 2$ (Age Cohort) $\times 2$ (Child Gender) $\times 2$ (Parent) MANOVA was also performed for the two Broadband factors of the CBCL. This analysis also showed a main effect for Risk Group $[F(4,798)=9.34, p<0.01]$. Univariate tests indicated that these effects were for both Externalizing Behavior Problems (EBPs) $[F(2,400)=18.16, p<0.01]$ and Internalizing Behavior Problems (IBPs) $[F(2,400)=3.31$, $p<0.05$ ]. Post-hoc comparisons indicated that children from AAL families had more EBPs than children from NAAL and control families $(p<0.05)$. Children from NAAL families also had greater EBPs than did children from control families $(p<0.05)$. Post-hoc tests also showed that children from AAL families had greater IBPs than children from control families $(p<0.05)$. The other groups did not differ.

A multivariate main effect also existed for Age Cohort $[F(2,399)=5.93, p<0.01]$. Univariate tests indicated that this effect was only significant for IBPs $[F(1,400)=4.77$, $p<0.05$ ), with older children showing greater IBPs than younger children.

A multivariate main effect was also found for Child Gender $[F(2,399)=6.78, p<0.01]$. Univariate tests indicated that these effects were for both EBPs $[F(1,400)=$ $5.98, p<0.05]$ and IBPs $[F(1,400)=13.52, p<0.01)$, with boys having greater problems in each area than girls.

Finally, with regard to the MANOVA on CBCL Broadband factors, a significant Risk Group $\times$ Age Cohort interaction was found $[F(4,798)=2.48, p<0.05]$. Univariate tests indicated that this effect was only significant for EBPs $[F(2,400)=3.29, p<0.05]$. Although younger children from AAL and control families had higher Externalizing Behavior scores than older children from these families, older children from NAAL families had higher scores than younger children from NAAL families (see Fig. 1 for a graphical representation of this interaction).

Intellectual Functioning and Academic Achievement. A 3 (Risk Group) $\times 2$ (Age Cohort) $\times 2$ (Child Gender) ANOVA on child IQ scores revealed a main effect for Risk Group $[F(2,200)=4.26, p<0.05]$. No significant main effects of Age Cohort or Child Gender, or any interactions were found. Post-hoc comparisons using the Tukey showed that children from AAL and NAAL families had lower intellectual functioning than children from control families.

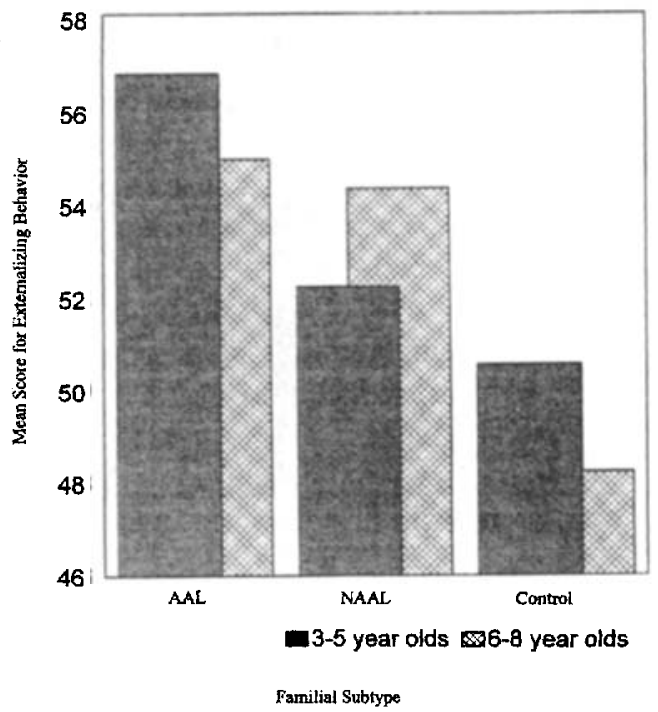

Fig. 1. Children's Externalizing Behavior-lamilial Risk Group $\times$ Age Cohort interaction. Note: Scores are aggregated across Child Gender and Parent Report.

No significant difference in intellectual functioning existed between children from AAL and NAAL families.

Due to the fact that achievement data were only collected on about one-third of the sample ( 80 of the 212 children) because the younger children were not yet in school, there was insufficient power to subdivide COAs into familial subtypes for analytic purposes. Thus, a 2 (Risk Group-COAs vs. Controls) $\times 2$ (Child Gender) MANOVA was performed on WRAT-R Reading, Spelling, and Arithmetic scores. Only a main effect for Risk Group $[F(3,74)=2.77, p<0.05]$ was found. Univariate tests indicated that these effects were in all three achievement areas: Reading $[F(1,76)=3.96, p<0.05]$, Spelling $[F(1,76)=7.42, p<0.01]$, and Arithmetic $[F(1,76)=$ $5.43, p<0.05]$. In all instances, COAs had lower scores than children from control families (Reading: Mean $_{\mathrm{COA}}=94.98$, $\mathrm{SD}_{\mathrm{COA}}=14.70, \mathrm{Mean}_{\text {Control }}=101.53, \mathrm{SD}_{\text {Control }}=14.03$; Spelling: Mean $_{\mathrm{COA}}=92.35, \mathrm{SD}_{\mathrm{COA}}=16.63$, Mean $_{\mathrm{Control}}=$ 102.53, $\mathrm{SD}_{\text {Control }}=15.70$; Arithmetic: Mean $_{\mathrm{COA}}=92.69$, $\mathrm{SD}_{\mathrm{COA}}=12.67, \mathrm{Mean}_{\text {Control }}=99.94, \mathrm{SD}_{\text {Control }}=14.71$ ).

Potential Effects of Mother's Functioning on Child Outcomes. Earlier evidence has shown that maternal psychopathology and adaptational characteristics vary across familial subtypes. ${ }^{30}$ To assess possible unique contributions to child outcomes due to the mother's level of functioning, a series of analyses of covariance (ANCOVAs) were run. The covariates chosen for these analyses were mother's antisociality (both during adulthood evaluated via the Adult ASB measure and during childhood evaluated via the Child ASB measure), and the LAPS indicator of her alcohol problem severity/chronicity. These variables were used because they most closely matched those of the father that were used to initially characterize the risk groups. Because we were interested in the variance unique to mothers rather than the shared variance between mothers and fathers as a function of assortative mating, covariates were calculated first by regressing mother's Adult ASB, Child ASB, and 
LAPS onto fathers' Adult ASB, Child ASB, and LAPS. Regressions were run separately for each of the three variables, and the residuals were saved and used as the covariates for further analyses. ANCOVAs were run only for significant main effects or interactions observed in the ANOVA and MANOVA analyses regarding child outcome variables already described.

Before running the ANCOVAs, the two necessary assumptions for conducting such analyses were tested: $:^{54}$ (1) that the covariates were related to the outcome variable and (2) that the regression slopes were homogeneous across cells. To test the first assumption, hierarchical regressions, including all three covariates, were run for each of the dependent variables. The unique contribution to $R^{2}$ was tested for each covariate $(p<0.05)$, and only those variables that provided a unique contribution to the variance were used as covariates in later analyses. All three potential covariates (LAPS, Adult ASB, and Child ASB) made unique contributions to the variance for $\mathrm{CBCL}$ Total Behavior Problems and Externalizing Behavior; only her Child ASB made unique contributions to the variance for CBCL Internalizing Behavior; and none of the covariates contributed significantly to the variance for IQ, WRAT-R Reading, WRAT-R Spelling, or WRAT-R Arithmetic (thus no covariate analyses were run on these four variables). In addition, because there was a lack of homogeneity of regression slopes across cells (the second assumption for covariate analyses), the covariates used in analyses were residualized cell-wise.

When the ANCOVAs were run on the pertinent variables, significant differences found in the initial set of analyses remained with the exception that the Risk Group $\times$ Age Cohort interaction for CBCL Externalizing Behavior and the Risk Group main effect for CBCL Internalizing Behavior were no longer significant. Thus, mothers' functioning independently contributed to these group differences, but not to the remainder of the findings previously presented.

\section{DISCUSSION}

The present study demonstrates that, even at very young ages, there are observable differences between children from alcoholic and nonalcoholic families. These differences uniformly involve poorer functioning among the COAs. The study also shows that identified differences in children's functioning are significantly related to the heterogeneity of the parental disorder, and in particular with regard to behavioral differences, where the subtype of parental alcoholism is a major differentiator of the level of child functioning. The present study thus replicates previous findings from our group ${ }^{30}$ and extends them by showing that such differences exist among female, as well as male, COAs. Interestingly, although gender differences were observed, the lack of statistical interactions with children's gender indicates that boys and girls may not be differen- tially sensitive to the effects of living with an alcoholic father during this stage of the children's development.

COAs had higher levels of behavior problems, compared with children from nonalcoholic homes. These results are consistent with past research showing higher levels of behavior problems among COAs. ${ }^{30,55-57}$ Furthermore, higher levels of problem behavior were present in COAs whose families carried greater risk burdens. This is again consistent with prior work, ${ }^{5,19,30,55-59}$ although the current study adds to previous findings by its use of a typology-based measure of risk burden, and by its finding that these differences are observable even when the children are very young. Whereas children from AAL and NAAL families scored higher on a measure of behavior problems than did children from nonalcoholic families, children from AAL families, exposed to substantially higher levels of various risk factors ${ }^{30}$ scored highest. This was true for young girls as well as boys, although boys scored even higher on behavior problems than did girls. As was the case with a recent study from our group, ${ }^{30}$ the present results lend support to a model of risk development that uses a cumulation/nesting theory for the aggregation of parental and family risk. It also demonstrates that such risk cumulation has similar effects on both young female and male offspring.

The fact that the results showed a similar pattern of behavior problems between boys and girls for Total Behavior Problems, Externalizing Behavior, and Internalizing Behavior is especially noteworthy. Lahey and Loeber ${ }^{61}$ have noted that girls have a later onset, as well as less externalizing behavior than do boys. However, the current results indicate that early vulnerabilities to aggressive and delinquent behavior are already evident among the female COAs, just as they are for male COAs, and that these vulnerabilities are greatest in those children from AAL families. Longitudinal work is necessary to determine if these relatively small differences (in terms of the absolute magnitude of problem behavior) between $\mathrm{COA}$ and control girls become even greater as these girls enter into adolescence and young adulthood, and if girls from the highest risk families continue to have the greatest problems. Such behavior, combined with more positive alcohol expectancies, has been shown to mediate alcohol involvement in young adults. ${ }^{19}$ Thus, contingent on the developmental trajectory with these girls, the present findings suggest markers for future alcohol problems and would provide support for the theory that there is at least a subset of female AALs with developmental trajectories similar to their male counterparts. ${ }^{18}$

We have no ready explanation for the interaction for externalizing behavior between risk group and child age. If one looks carefully at the data shown in Table 3 , it becomes clear that the effect is attributable to differences in ratings of girls from NAAL families; primarily to higher ratings of the older (6-through 8-year-olds) girls among this subtype. This pattern is different from the other two risk groups. Moreover, this interaction was no longer significant when 
the mother's variables were covaried out of the analyses, indicating that the level of mother pathology plays some role in the effect. One possible explanation is that the mothers in NAAL families become relatively more challenged as the girls reach school age, which in turn impacts the behavior of their older daughters. However, it should also be noted that the number of girls in this older, NAAL subgroup is one of the smaller groups of the study, and the results may simply be a statistical artifact. It will be useful to see if these differences remain when other ratings of current behavior (i.e., teachers' and perhaps the child's own view of himself/herself) are examined as the children grow older.

\section{Intellectual Functioning and Academic Achievement}

The present investigation also found that offspring of alcoholics had lower levels of intellectual functioning than did children whose parents were not alcoholic. Past research has observed lower IQs in COAs, ${ }^{62-65}$ although some studies have not found the effect. ${ }^{4,66-68}$ One explanation for the discrepant findings has been the possibility of sampling differences pertaining to the parents' alcoholism subtype. ${ }^{69}$ In fact, a preliminary investigation from our group showed that $\mathrm{IQ}$ differences between female COAs and non-COAs occurred only among girls coming from AAL homes. ${ }^{69}$ In the present larger scale investigation, lower IQs were observed among both groups of children from alcoholic homes, with no reliable difference present between children from AAL and NAAL families. The failure to find subtype differences remains to a degree puzzling, given the subtype variations in parental IQ already observed among these families (Bingham et al. unpublished data). One possibility is that these results will only become observable with increasing age of the children. Another is that they simply do not exist. From this perspective, the differences observed among the adults may be attributable to the long-term effects of their own alcoholism, as well as differences in environmental adversity known to exist among the subtypes. 22,26

It should also be noted that although IQs differed between children from alcoholic and control homes, the COA children were still functioning within the normal range. Nevertheless, these results provide additional evidence for a somewhat lower level of intellectual functioning among COAs even at very early stages of development, although without the presence of subtype variability. Further investigations are needed to better understand the discrepancy in findings across studies, with the special need to examine possible specific ability differences that make up such overall intellectual functioning indicators as IQ. This is especially important given the research showing that specialized cognitive functions, in particular involving verbal ability, classification skills, and planning ability, most clearly distinguish COAs from non-COAs. ${ }^{70}$

The current study also found differences between COAs and non-COAs regarding the academic achievement of the children. COAs demonstrated lower levels of Reading, Spelling, and Arithmetic achievement. These results are consistent with previous research findings indicating that COAs show impaired academic functioning relative to nonCOAs. ${ }^{63,64,71,72}$ Potential differences relating to subtype variability could not be analyzed because the majority of the sample had not reached school age. However, such investigations would be useful in the future.

\section{Maternal Effects}

Although the study's strategy for alcoholic subtyping was based on the father's level of alcoholism and antisociality, mother's contributions were also examined in the analyses. The direct contribution of the mother's functioning, above and beyond that accounted for by assortative coupling, had little effect on observed group differences with a couple of exceptions. Nonetheless, mother differences have already indirectly entered into these analyses, given the demonstrated differences in assortative mating noted among AALs, NAALs, and Controls. ${ }^{26,30}$ These studies have noted the co-aggregation of father antisociality differences, with differences in mother psychopathology (e.g., more antisocial behavior, higher levels of drinking problems, more depression) and social adaptation (e.g., less education). Thus, the subtype differences reported herein, although based on a classification of families by way of father functioning, indirectly were also accessing maternal covariation.

Maternal factors did uniquely contribute to the determination of differences in children's internalizing behavior. In particular, unique maternal psychopathology variance, involving a combined indicator of lifetime extent of alcohol problems and antisociality, explained a significant portion of the observed group difference between children from AAL, NAAL, and control families. In this regard, Chassin et al. ${ }^{55}$ found a unique effect attributed to maternal alcoholism regarding internalizing symptomatology among adolescent children. Steinhausen et al. ${ }^{73}$ found an association between maternal alcoholism and emotional disturbance, but not conduct disorder, among child outpatients (mean age of the children was eight) in a psychiatric setting. Thus, the present results, albeit assessing maternal functioning in other areas as well as alcohol problems, also show that this variation is especially important in predicting COAs variation in Internalizing Behavior. From a cumulation of risk perspective, it appears that the risk burden for young children that predicts their Internalizing Behavior is mediated by factors to a greater degree related to maternal psychopathology, whereas their Externalizing Behavior is not (the exception possibly being the Externalizing Behavior of 6 through 8-year-old girls from NAAL families as mentioned previously). However, in both the current study and that of Chassin et al., the observed effects of mothers' contributions on children's internalizing symptomatology were assessed through parent reports of child behavior. Children's 
report of their functioning in these areas was not assessed herein due to their young age, and no effect of maternal alcoholism appeared when youth reports of Internalizing Behavior were used in the Chassin et al. analyses. Thus, as noted by Chassin et al., the effects of mothers' functioning on child Internalizing Behavior must be interpreted with caution, and further investigation is needed.

\section{Concluding Observations}

Given the observed differences between both boys and girls in behavioral and cognitive functioning, the present study continues to support evidence from our earlier reports that COA effects are documentable very early in developmental course. ${ }^{30}$ The results were predicted on the basis of theory, and they are consistent with a continuity of risk perspective. They are also consistent with several other studies of early adaptation, ${ }^{74,75}$ raising the important question about what the factors are that may sustain or dilute such differences over time. From a prevention perspective, the ability to find an answer to this question is critical.

Nonetheless, there are limitations of the current study, some of which have already been identified. First, even though developmental variation is considered to be an important factor, the current work is cross-sectional. Prospective tracking of these domains is essential, so that developmental changes may be identified. Second, this study examined children's functioning beginning at a very young age. As part of a longitudinal study focusing on risk factors and child development, it is important to document early differences between alcoholic and nonalcoholic families. However, many problems occur at very low base rates among young children, making the task of identifying possible differences a more difficult one.

Finally, in contrast to the assessment of intellectual and academic functioning, behavior problems were assessed only through parent reports. Thus, there is a possibility that the results obtained, at least in part, reflect parental perception differences between groups, rather than actual behavior differences among the children. This is especially an issue since the level of psychopathology differs substantially among the risk groups. Some prior research on the CBCL has suggested that this may not be an overriding limitation, because psychologically distressed parents do not always rate their children as more disturbed than normal parents. ${ }^{76}$ Some studies have also shown parents with psychopathology to rate their children similarly to independent rater sources such as teachers. ${ }^{77,78}$ Yet, the debate continues as to whether greater behavioral problems among children of parents with greater psychopathology are more a function of parents' negative perceptions or of actual behavior difficulties in the children. ${ }^{79}$ In the present study, the fact that other group differences were detected involving observed rather than perceived variables in the present study (i.e., the IQ and achievement scores), and involving behavioral ratings by observers in other studies of these families, ${ }^{80}$ provides further support for the conclusion that the child behavior findings are not simply a function of parents' perceptions. Nevertheless, future studies should continue to obtain information about child functioning from multiple sources to reduce potential biases based on single source reporting of behavior problems.

\section{REFERENCES}

1. El-Guebaly N, Offord DR: The offspring of alcoholics: A critical review. Am J Psychiatry 134:357-365, 1977

2. Sher KJ: Children of Alcoholics: A Critical Appraisal of Theory and Research. Chicago, The University of Chicago Press, 1991

3. West MO, Prinz RJ: Parental alcoholism and childhood psychopathology. Psychol Bull 102:204-218, 1987

4. Fitzgerald HE, Sullivan LA, Ham HP, Zucker RA, Bruckel S. Schneider AM, Noll RB: Predictors of behavior problems in three-yearold sons of alcoholics: Early evidence for the onset of risk. Child Dev 64:110-123, 1993

5. Johnson SL, Jacob T: Psychosocial functioning in children of alcoholic fathers. Psychol Addict Behav 9:101-113, 1995

6. Tarter R, Kabene M, Escallier E, Laird S, Jacob T: Temperament deviation and risk for alcoholism. Alcohol Clin Exp Res 14:380-382, 1990

7. Babor TF: The classification of alcobolics. Alcohol Health Res World 1:6-14, 1996

8. Cloninger CR, Bohman M, Sigvardsson S: Inheritance of alcohol abuse. Arch Gen Psychiatry 38:861-868, 1981

9. Zucker RA: The four alcoholisms: A developmental account of the etiologic process, in Rivers PC (ed): Nebraska Symposium on Motivation: Alcohol and Addictive Behavior, vol 34. Lincoln, University of Nebraska Press, 1987, pp 27-83

10. Zucker RA: Pathways to alcohol problems and alcoholism: A developmental account of the evidence for multiple alcoholisms and for contextual contributions to risk, in Zucker RA, Howard J, Boyd GM (eds): The Development of Alcohol Problems: Exploring the Biopsychosocial Matrix of Risk (Research Monograph 26). Rockville, MD, National Institute on Alcohol Abuse and Alcoholism, 1994, pp 225-289

11. Clonninger $C R$ : Neurogenetic adaptive mechanisms in alcoholism. Science 236:410-416, 1987

12. Zucker RA, Ellis DA, Fitzgerald HE: Developmental evidence for at least two alcoholisms. I. Biopsychosocial variation among pathways into symptomatic difficulty, in Babor TF, Hesselbrock V, Meyer RE. Shoemaker W (eds): Types of Alcoholics: Evidence from Clinical, Experimental, and Genetic Research. New York, The New York Academy of Sciences, 1994, pp 134-146

13. Zucker RA, Ellis DA, Fitzgerald HE, Bingham CR, Sanford KP: Other evidence for at least two alcoholisms. Il. Life course variation in antisociality and heterogencity of alcoholic outcome. Dev Psychopathol 8:831-848, 1996

14. Caplan HM: Subtypes of Alcoholic Women. Unpublished doctoral dissertation, Department of Psychology, Michigan State University, East Lansing, MI, 1996

15. Gomberg ESL, Nirenberg TD: Antecedents and consequences, in Gomberg ESL, Nirenberg TD (eds): Women and Substance Abuse. Norwood, NJ, Ablex Publishing, 1993, pp 118-141

16. Hill SY: Genetic vulnerability to alcoholism in women, in Gomberg ESL, Nirenberg TD (eds): Women and Substance Abuse. Norwood, NJ, Ablex Publishing, 1993, pp 42-61

17. Wilsnack SC, Wilsnack RW: Epidemiological research on women's drinking: Recent progress and directions for the 1990s, in Gomberg ESL, Nirenberg TD (eds): Women and Substance Abuse. Norwood, NJ, Ablex Publishing, 1993, pp 62-99

18. Zucker RA, Gomberg ESL: Alcoholism and Antisocial Comorbidity in Women: A Note on a Hot Spot and Some Hypotheses. Ann Arbor, University of Michigan Alcohol Research Center, 1994

19. Sher KJ, Walitzer KS, Wood PK, Brent EE: Characteristics of 
children of alcoholics: Putative risk factors, substance use and abuse, and psychopathology. J Abnorm Psychol 100:427-448, 1991

20. Moos RH, Billings AG: Children of alcoholics during the recovery process: Alcoholic and matched control families. Addict Behav 7:155-163, 1982

21. Rimmer J: The children of alcoholics: An exploratory study, Child Youth Services Rev 4:365-373, 1982

22. Zucker RA, Fitzgerald HE, Moses HD: Emergence of alcohol problems and the several alcoholisms: A developmental perspective on etiologic theory and life course trajectory, in Cicchetti D, Cohen DJ (eds): Developmental Psychopathology: Risk, Disorder, and Adaptation, vol 2. New York, Wiley, 1995, pp 677-711

23. Schuckit M: Alcoholism and sociopathy: Diagnostic confusion. Q J Stud Alcohol 34:154-164, 1973

24. Hesselbrock M, Meyer R, Keener J: Psychopathology in hospitalized alcoholics. Arch Gen Psychiatry 42:1050-1055, 1985

25. Babor T, Holmann M, Delboca F, Hesselbrock V, Meyer R, Dolinsky Z, Rounsaville B: Types of alcoholics. I. Evidence for an empirically derived typology based on indicators of vulnerability and severity. Arch Gen Psychiatry 49:599-608, 1992

26. Zucker RA, Ellis DA, Bingham CR, Fitzgerald HE: The development of alcoholic subtypes: Risk variation among alcoholic families during the early childhood years. Alcohol Health Res World 20:46-54, 1996

27. Ichiyama M, Zucker RA, Fitzgerald HE, Bingham CR: Articulating subtype differences in self and relational experience among alcoholic men via Structural Analysis of Social Behavior. J Consult Clin Psychol 64:12451254,1995

28. Daugherty MK, Zucker RA, Floyd F, Bingham CR, Fitzgerald HE: Dominance and Struggles for Power in Alcoholic Marital Interactions: Alcoholic Subtype Variations. Unpublished paper, Department of Psychology, Michigan State University, East Lansing, MI, 1996

29. Deleted in proof

30. Deleted in proof

31. American Psychiatric Association: Diagnostic and Statistical Manual, ed 4. Washington, D.C., 1994

32. Caetano R, Kaskutas LA: Changes in drinking patterns among Whites, Blacks, and Hispanics. J Stud Alcohol 56:558-565, 1995

33. Herd D: Predicting drinking problems among black and white men: Results from a national survey. J Stud Alcohol 55:61-71, 1994

34. U.S. Government: Economic Report of the President. Washington, D.C., U.S. Government Printing Office, February 1998

35. Stevens G, Featherman DL: A revised socioeconomic index of occupational status. Soc Sci Res 10:364-395, 1981

36. Mueller CW, Parcel TL: Measures of socioeconomic status: Alternatives and recommendations. Child Dev 52:13-30, 1981

37. Selzer ML, Vinokur A, Van Rooijen L: A self-administered short Michigan Alcoholism Screening Test (SMAST). J Stud Alcohol 36:117126,1975

38. Robins L, Helzer J, Croughan J, Ratcliff KS: The NIMH Diagnostic Interview Schedule: Its History, Characteristics and Validity. St. Louis, MO, Washington University School of Medicine, 1980

39. Deleted in proof

40. Deleted in proof

41. Ham HP, Fitzgerald HE, Zucker RA: Recent evidence of behavioral dysregulation in sons of male alcoholics. Paper presented at the Research Society on Alcoholism Scientific Conference, San Antonio, TX, June 1993

42. Zucker RA, Barron FH: Parental behaviors associated with problem drinking and antisocial behavior among adolescent males, in Chafetz ME (ed): Research on Alcoholism. I. Clinical Problems and Special Populations (DHEW Publ. No. 74-675). Washington, D.C., Government Printing Office, 1973, pp 276-296

43. Zucker RA, Fillmore KM: Motivational Factors and Problem Drinking Among Adolescents. Paper presented at the 28th International Congress on Alcohol and Alcoholism, Washington, D.C., September 1968 44. Deleted in proof

45. Zucker RA: Scaling the developmental momentum of alcoholic process via the Lifetime Alcohol Problems Score. Alcohol Alcohol (Suppl. 1):505-510, 1991

46. American Psychiatric Association: Diagnostic and Statistical Manual, ed 3-rev. Washington, D.C., 1987

47. Zucker RA, Davies WH, Kincaid SB, Fitzgerald HE, Reider EE: Conceptualizing and scaling the developmental structure of behavior disorder: The Lifetime Alcohol Problems Score as an example. Dev Psychopathol 9:1-19, 1997

48. Achenbach T: Manual for the Child Behavior Checklist/4-18 and 1991 Profile. Burlington, VT, University of Vermont, Department of Psychiatry, 1991

49. Bird H, Gould M, Rubio-Stipec M, Staghezza B, Canino G: Screening for childhood psychopathology in the community using the Child Behavior Checklist. J Am Acad Child Adolesc Psychiatry 30:116-123, 1991

50. Wechsler D: Wechsler Intelligence Scale for Children-Revised. New York, The Psychological Corporation, 1974

51. Terman LM, Merrill MA: Stanford-Binet Intelligence Scale: Manual for the Third revision (Form L-M). Boston, Houghton Mifflin, 1973

52. Sattler JM: Assessment of Children's Intelligence and Special Abilities, ed 2. Boston, Allyn \& Bacon, 1982

53. Jastak S, Wilkinson GS: The Wide Range Achievement Test-Revised: Administration Manual. Wilmington, DE, Jastak Associates, 1984

54. Neter J, Kutner MH, Nachtsheim CJ, Wasserman W: Applied Linear Statistical Models: Regression, Analysis of Variance, and Experimental Designs, ed 4. Homewood, IL, Irwin, 1996

55. Chassin L, Rogosch F, Barrera M: Substance use and symptomatology among adolescent children of alcoholics. J Abnorm Psychol 100: $449-463,1991$

56. Jacob T, Leonard K: Psychosocial functioning in children of alcoholic fathers, depressed fathers, and control fathers. J Stud Alcohol 47: 373-380, 1986

57. Rubio-Stipec M, Bird H, Canino G, Bravo M, Alegria M: Children of alcoholic parents in the community. J Stud Alcohol 52:78-88, 1991

58. Finn P, Earleywine M, Pihl RO: Sensation seeking, stress reactivity and alcohol dampening discriminate the density of family history of alcoholism. Alcohol Clin Exp Res 16:585-590, 1992

59. Pihl RO, Peterson J, Finn P: An heuristic model for the inherited predisposition to alcoholism. Psychol Addict Behav 4:12-25, 1990

60. Deleted in proof

61. Lahey BB, Loeber R: Framework for a developmental model of oppositional defiant disorder and conduct disorder, in Routh DK (ed): Disruptive Behavior Disorders in Childhood. New York, Plenum Press, 1994, pp 139-180

62. Bennett LA, Wolin SJ, Reiss D: Cognitive, behavioral, and emotional problems among school-age children of alcoholic parents. Am J Psychiatry 145:185-190, 1988

63. Ervin C, Little R, Streissguth A, Beck D: Alcoholic fathering and its relation to child's intellectual development: A pilot investigation. Alcohol Clin Exp Res 8:362-365, 1984

64. Gabrielli W, Mednick S: Intellectual performance in children of alcoholics. J Nerv Ment Dis 171:444-447, 1983

65. Steinhausen $H$, Nestler V, Huth H: Psychopathology and mental functions in the offspring of alcoholic and epileptic mothers. J Am Acad Child Psychiatry 21:268-273, 1982

66. Herjanic B, Herjanic M, Wetzel R, Tomelleri C: Substance abuse: Its effect on offspring. Res Commun Psychol Psychiatry Behav 3:65-75, 1978

67. Johnson JL, Rolf JE: Cognitive functioning in children from alcoholic and nonalcoholic familics. Br J Addict 83:849-857, 1988

68. Tarter R, Hegedus A, Goldstein G, Shelly C, Alterman A: Adolescent sons of alcoholics: Neuropsychological and personality characteristics. Alcohol Clin Exp Res 8:216-222, 1984

69. Puttler LI, Zucker RA, Fitzgerald HE, Bingham CR: Outcome differences among female COAs during early and middle childhood as a function of paternal recovery status. Alcohol Clin Exp Res 21(Suppl., RSA Abstracts):127A, 1997 
70. Pihl RO, Bruce KR: Cognitive impairments in children of alcoholics. Alcohol Health Res World 19:142-147, 1995

71. Hegedus AM, Alterman AI, Tarter RE: Learning achievement in sons of alcoholics. Alcohol Clin Exp Res 8:330-333, 1984

72. Marcus AM: Academic achievement in elementary school children of alcoholic mothers. J Clin Psychol 42:372-376, 1986

73. Steinhausen H, Gobel D, Nestler V: Psychopathology in the offspring of alcoholic parents. J Am Acad Child Psychiatry 23:465-471, 1984

74. Caspi A, Moffitt TE, Newman DL, Silva EA: Behavioral observations at age 3 years predict adult psychiatric disorders: Longitudinal evidence from a birth cohort. Arch Gen Psychiatry 53:1033-1039, 1996

75. Eron LD, Huesmann LR, Dubow E, Romanoff R, Yarmel PW: Aggression and its correlates over 22 years, in Crowell DH, Evans IM, O'Donnell CR (eds): Childhood Aggression and Violence. New York, Plenum, 1987, pp 249-262
76. Conrad M, Hammen C: Role of maternal depression in perceptions of child maladjustment. J Consult Clin Psychol 57:663-667, 1989

77. Richters J, Pellegrini D: Depressed mother's judgements about their children: An examination of the depression-distortion hypothesis. Child Dev 60:1068-1075, 1989

78. Loukas A, Piejak LA, Mun E-Y, Bingham CR, Fitzgerald HE, Zucker RA: Across Context Consistency of Child Behavior Problems Among Parents and Teachers in High and Low Psychopathology Families. Poster presented at the Biennial Meeting of the Society for Research in Child Development, Washington, D.C., 1997, April

79. Field T: Infants of depressed mothers. Dev Psychopathol 4:49-66, 1992

80. Whipple E, Fitzgerald HE, Zucker RA: Parent-child interactions in alcoholic and non-alcoholic families. Am J Orthopsychiatry 65:153-159, 1995 